\title{
Effect of renalase (RNLS) gene polymorphisms (rs1088700 and rs2576178) on plasma RNLS level in hemodialyzed patients affected by arterial hypertension and coronary artery disease
}

\begin{abstract}
Introduction. We have previously reported that rs 10887800 and rs 2576178 renalase $(R N L S)$ single nucleotide polymorphisms (SNPs) are associated with the susceptibility to arterial hypertension (HY) and coronary artery disease (CAD) in hemodialyzed patients (HD). However, the underlying mechanism of this link remains undefined.

Aim. In the present study we examine the influence of above-mentioned $R N L S$ gene variants on plasma renalase level in subgroups of HD patients affected by HY and CAD.

Material and methods. In total, 309 hemodialyzed patients participated in the study (157 males and 152 females, mean age $64.1 \pm 14.10$ years). Rs10887800 and rs2576178 RNLS gene polymorphisms were genotyped using PCR-RFLP method. Plasma RNLS level was assessed by ELISA (USCN Life Science Inc., Wuhan, China). The data were analyzed using SPSS Statistics 23.

Results. Regarding rs10887800 polymorphism, hypertensive AA homozygotes had significantly lower plasma RNLS level $(28.93 \pm 9.94 \mu \mathrm{g} / \mathrm{mL})$ compared to AG $(34.06 \pm 12.79 \mu \mathrm{g} / \mathrm{mL})$ and $\mathrm{GG}$ carriers $(36.54 \pm 12.01 \mu \mathrm{g} / \mathrm{mL}), \mathrm{p}=0.002$. Among CAD patients no differences in plasma RNLS concentrations between rs10887800AA, AG and GG carriers were observed (31.52 \pm 10.95 $\mu \mathrm{g} / \mathrm{mL}, 34.75 \pm 13.37 \mu \mathrm{g} / \mathrm{mL}, 34.44 \pm 13.10 \mu \mathrm{g} / \mathrm{mL}$, respectively), $\mathrm{p}=0.615$. For the rs 2576178 variant, both $\mathrm{HY}$ and CAD participants did not differ in terms of plasma RNLS levels with regard to the particular genotypes, $\mathrm{p}>0.050$.

Conclusion. Obtained results extend our previous findings and indicate for the first time that rs10887800 RNLS gene variant modifies the level of plasma RNLS in hemodialyzed patients with HY but not in those with CAD. The study provides, thus, a new insight into the potential mechanisms through which $R N L S$ gene variants modulate the risk of cardiovascular diseases among patients with end-stage kidney disease.
\end{abstract}

Keywords: cardiovascular abnormalities, renal dialysis, polymorphism, genetics.

DOI: $10.1515 /$ pjph-2017-0031

\section{INTRODUCTION}

Patients with end stage kidney disease (ESKD) are at heightened risk of cardiovascular diseases (CVDs), among which coronary artery disease (CAD) is the most common (39\% of all CVDs) [1]. The prevalence of arterial hypertension (HY) is about $90 \%$ at the beginning of renal replacement therapy (RRT) [2]. Compared with age-matched general population, mortality rate in dialysis patients is 10-20-fold higher and $50 \%$ of such deaths are related to CAD [3]. High prevalence of well-known cardiovascular risk factors (CVRFs) does not explain such a high CVD burden in uremic patients [4]. Thus, identification of a novel CVRF is crucial for better risk prediction and cardiac mortality prevention in this population.

Human renalase (RNLS), also called MAO-C, is suggested to be the missing link between heart and kidney diseases. RNLS is a FAD-dependent amine oxidase secreted into blood mainly by kidneys and degradates circulating catecholamines. RNLS is considered to play a role in the regulation of sympathetic tone, blood pressure and cardiac function [5].

$R N L S$ gene is located on chromosome 10q23.31, spans 311 $\mathrm{kb}$ in length and encodes 16 exons. In our recent studies single nucleotide polymorphisms (SNPs) in $R N L S$ were associated with susceptibility to CVDs in hemodialyzed population. The G allele carriers of rs10887800 and rs2567178 SNPs had an increased risk of HY, whereas rs10887800GG genotype was related to CAD [6,7]. However, the underlying mechanism involved in this relationship remains undefined.

\section{AIM}

Therefore, the aim of the present study is to extend our previous findings by evaluating the effects of rs10887800 and rs2576178 RNLS SNPs on plasma renalase level in subsets of HD patients affected by HY and CAD. Additionally, to clarify the functional importance of renalase, the relationship between RNLS and selected CVRFs will be investigated.

\section{MATERIAL AND METHODS}

The study was conducted from January 2012 to December 2013 and involved 309 Caucasian hemodialyzed participants (157 males, 152 females, mean age 64.1 \pm 14.1 years) from 5 dialysis units in eastern Poland. All patients were on standard 
bicarbonate dialysis (SBD). Diabetes mellitus was the most common cause of ESRD (23\%). For the purpose of the study participants were classified into 4 subsets based on the presence $(\mathrm{HY}+, \mathrm{n}=259)$ or absence (HY-, $\mathrm{n}=50)$ of $\mathrm{HY}$ and the presence $(\mathrm{CAD}+, \mathrm{n}=107)$ or absence $(\mathrm{CAD}-, \mathrm{n}=202)$ of $\mathrm{CAD}$. According to $\mathrm{K} / \mathrm{DOQI}$ guidelines, $\mathrm{HY}$ was defined as systolic blood pressure (SBP) of $\geq 140 \mathrm{mmHg}$ and/or a diastolic (DBP) of $\geq 90 \mathrm{mmHg}$ and/or history of current antihypertensive treatment [8]. The diagnosis of CAD was based on the criteria of the European Society of Cardiology (ESC). The exclusion criterium was the presence of other heart diseases such as cardiomyopathy, pericarditis or aortic stenosis. Clinical, demographic and laboratory data were collected on the basis of medical interview, physical examination and patients' medical records. The arithmetic means of predialysis, systolic and diastolic BP, recorded for 2 weeks, were used for the analysis. Hemodialysis adequacy was assessed by a calculator, which uses the Daugirdas II equation formula for single pool Kt/V for urea (spKt/Vurea). The presence of residual renal function (RRF) was defined as the urine amount above $100 \mathrm{ml} /$ day. The results of plasma RNLS level, genotype distribution and allele frequencies of rs10887800 and rs2576178 RNLS SNPs were taken from our previous studies [7,9]. All participants signed an Informed Consent Form. The study protocol was approved by the Bioethical Board of the Medical University of Lublin (No. KE-0254/154/2013).

\section{Assays}

Blood samples were drawn from the venous part of the vascular access at the beginning of hemodialysis session. Renalase concentrations were measured by commercially available ELISA kit from USCN Life Science Inc. (Wuhan, China).

\section{Investigation of $\mathbf{r s 1 0 8 8 7 8 0 0}$ and $r \mathbf{2 5 7 6 1 7 8}$ renalase gene polymorphisms}

Human genomic DNA was derived form peripheral blood leucocytes, prepared by a standard procedure and stored at $-70^{\circ} \mathrm{C}$ before use. SNPs were investigated by polymerase chain reaction - restriction fragment length polymorphism (PCR-RFLP) technique. Primers sequences, restriction endonuclease enzymes and the size of restriction fragments obtained from PCR-RFLP reaction are shown in Table 1. Amplification was performed in a PTC-200 Thermal Cycler (MJ Research, Inc. Waltham, MA). Genomic DNA (300ng) was amplified using the following conditions: initial denaturation at $95^{\circ} \mathrm{C}$ for $6 \mathrm{~min}$, followed by 35 cycles at $94^{\circ} \mathrm{C}$ for 30 s, annealing at $60^{\circ} \mathrm{C}$ for $30 \mathrm{~s}$ and extension at $72^{\circ} \mathrm{C}$ for 1 minute. The final extension step was at $72^{\circ} \mathrm{C}$ for 7 minutes. The resulting DNA fragments were separated by electrophoresis on $2.5 \%$ agarose gel.

\section{Statistical Analysis}

Data analysis was performed using the SPSS Statistics 23.0 software (IBM Corp., Armonk, NY, USA). All tests were twosided and the $\mathrm{p}$ value $<0.050$ indicated statistical significance. Deviation from Hardy-Weinberg equilibrium (HWE) expectations was evaluated by $\chi^{2}$ goodness-of-fit test. The means of variables were compared by a student's t test (continous variables) or $\chi^{2}$ test of independence (discrete variables). The correlations of variables were computed with the Spearman's rank correlation coefficient. ANCOVA (analysis of covariance) was used to assess the effect of $R N L S$ genotypes on plasma RNLS level after adjustment for potentially confounding effect of age, gender, BMI, hemoglobin and albumin level, the presence of hypercholesterolemia and RRF. For post-hoc analyses Sidak's correction test was performed.

TABLE 1. Primers sequences, restriction endonuclease enzymes and size of restriction fragments obtained from PCR-RFLP reaction.

\begin{tabular}{clcc}
\hline $\begin{array}{c}\text { Gene } \\
\text { variants }\end{array}$ & \multicolumn{1}{c}{ Primer sequence (5'-3') } & Restriction enzyme & Fragment sizes \\
Undigested (A allele) & Polymorphic variant (G allele) \\
\hline Rs10887800 & F: CAGGAAAGAAAGAGTTGACAT & Pst I & $554 \mathrm{bp}$ \\
\hline Rs:AAGTTGTTCCAGCTACTGT 576178 & F:AGCAGAGAAGCAGCTTAACCT & & $515+139 \mathrm{bp}$ \\
& R:TTATCTGCAAGTCAGCGTAAC & Msp I & $423+102 \mathrm{bp}$ \\
\hline
\end{tabular}

TABLE 2. Demographic and clinical characteristics of studied subgroups.

\begin{tabular}{|c|c|c|c|c|c|c|}
\hline \multirow{3}{*}{ Characteristics } & \multicolumn{2}{|c|}{ Arterial hypertension } & \multirow{3}{*}{ p value* } & \multicolumn{2}{|c|}{ Coronary artery disease } & \multirow{3}{*}{ p value* } \\
\hline & $\mathbf{H Y}+$ & HY- & & CAD+ & CAD- & \\
\hline & $(n=259)$ & $(\mathrm{n}=\mathbf{5 0})$ & & $(n=107)$ & $(n=202)$ & \\
\hline Age (years) & $64.01 \pm 14.04$ & $64.62 \pm 14.31$ & $>0.050$ & $69.61 \pm 10.51$ & $61.20 \pm 14.83$ & $<0.001$ \\
\hline \multicolumn{7}{|l|}{ Gender } \\
\hline Male, n (\%) & $138(53.3)$ & $19(38)$ & \multirow{2}{*}{$<0.050$} & $64(59.81)$ & $93(46.03)$ & $<0.001$ \\
\hline Female, n (\%) & $121(46.7)$ & $31(62)$ & & $43(40.19)$ & $109(53.97)$ & $<0.001$ \\
\hline \multicolumn{7}{|l|}{ Laboratory parameters } \\
\hline BMI (kg/m2) & $25.83 \pm 5.28$ & $25.44 \pm 5.55$ & $>0.050$ & $27.47 \pm 5.62$ & $24.87 \pm 4.93$ & $<0.001$ \\
\hline Hemoglobin $(\mathrm{g} / \mathrm{dl})$ & $10.54 \pm 1.41$ & $10.95 \pm 1.43$ & $>0.050$ & $10.6 \pm 1.3$ & $11.0 \pm 1.45$ & $<0.050$ \\
\hline Albumin (g/dl) & $3.94 \pm .38$ & $3.97 \pm .42$ & $>0.050$ & $3.86 \pm .36$ & $3.98 \pm .39$ & $<0.050$ \\
\hline Hyperlipidemia, n (\%) & $130(50.8)$ & $22(44)$ & $>0.050$ & $65(61.3)$ & $87(43.5)$ & $<0.010$ \\
\hline Renalase $(\mu \mathrm{g} / \mathrm{mL})$ & $33.23 \pm 12.20$ & $35.19 \pm 13.26$ & $>0.050$ & $33.95 \pm 12.74$ & $33.33 \pm 12.21$ & $>0.050$ \\
\hline Dialysis vintage (yrs) & $5.93 \pm 5.72$ & $8.48 \pm 8.53$ & $<0.050$ & $6.01 \pm 6.16$ & $6.52 \pm 6.40$ & $>0.050$ \\
\hline Smoking, n (\%) & $43(16.6)$ & $5(10)$ & $>0.050$ & $21(19.6)$ & $27(13.4)$ & $>0.050$ \\
\hline Alcoholism, n (\%) & $7(2.7)$ & $1(2)$ & $>0.050$ & $2(1.9)$ & $6(3)$ & $>0.050$ \\
\hline CVD in $\mathrm{FH}, \mathrm{n}(\%)$ & $39(15.1)$ & $3(6)$ & $>0.050$ & $21(19.6)$ & $21(10.4)$ & $<0.010$ \\
\hline
\end{tabular}

Continuous variables are presented as means \pm SD. Discrete variables are presented as numbers and percentages (in parentheses). HY - arterial hypertension, CAD - coronary artery disease, BMI - Body Mass Index, CVD - cardiovascular disease, FH - family history. * t-student or $\chi^{2}$ tests. 


\section{RESULTS}

\section{Characteristics of the study population}

Clinical and demographic characteristics of the study participants are summarized in Table 2. Compared with HY- group, hypertensive patients were more frequently male $(53.3 \%$ vs $38 \%)$ and had shorter dialysis vintage $(5.93 \pm 5.72$ vs $8.48 \pm 8.53$ years). Compared with CAD-, patients with CAD were older (69.61 \pm 10.51 vs $61.20 \pm 14.83$ years) and more often male. They had lower hemoglobin and albumin level and higher prevalence of hyperlipidemia. $\mathrm{CAD}+$ patients were also more likely to have a positive family history of CVDs and higher BMI value. Mean plasma RNLS concentration in the study cohort was $33.54 \pm 12.37$ $\mu \mathrm{g} / \mathrm{mL}$. There were no differences in plasma RNLS level neither between patients with and without HY $(33.23 \pm 12.20$ $\mu \mathrm{g} / \mathrm{mL}$ vs $35.19 \pm 13.26 \mu \mathrm{g} / \mathrm{mL}$, respectively), $\mathrm{p}>0.050$ nor between patients with and without CAD $(33.95 \pm 12.74 \mu \mathrm{g} / \mathrm{mL}$ vs $33.33 \pm 12.21 \mu \mathrm{g} / \mathrm{mL}$, respectively) $\mathrm{p}>0.050$.

Effect of $R N L S$ gene polymorphisms (rs1088700 and rs2576178) on plasma renalase level depending on the comorbidity

Genotype distribution of studied polymorphisms was consistent with Hardy-Weinberg equilibrium (rs10887800 SNP: $\chi^{2}=0.18, \mathrm{p}=0.669$ for $\mathrm{CAD}+, \chi^{2}=1.80, \mathrm{p}=0.180$ for CAD-, $\chi^{2}=0.04, \mathrm{p}=0.833$ for $\mathrm{HY}+, \chi^{2}=2.16, \mathrm{p}=0.142$ for $\mathrm{HY}-$; rs2576178 SNP: $\chi^{2}=0.11, \mathrm{p}=0.735$ for $\mathrm{CAD}+, \chi^{2}=0.02, \mathrm{p}=0.888$ for CAD-, $\chi^{2}=0.10, p=0.755$ for $\mathrm{HY}+, \chi^{2}=0.01, \mathrm{p}=0.938$ for HY-). As shown in Table 3, regarding rs10887800 polymorphism, hypertensive AA homozygotes had significantly lower plasma RNLS level $(28.93 \pm 9.94 \mu \mathrm{g} / \mathrm{mL})$ compared to AG $(34.06 \pm 12.79 \mu \mathrm{g} / \mathrm{mL})$ and $\mathrm{GG}$ carriers $(36.54 \pm 12.01 \mu \mathrm{g} / \mathrm{mL})$, $\mathrm{p}=0.002$. Among $\mathrm{CAD}$ patients no differences in plasma RNLS concentrations between rs10887800AA, AG and GG carriers were observed, $p=0.615$. For the rs 2576178 variant, both $\mathrm{HY}$ and CAD participants did not differ in terms of plasma RNLS levels with regard to the particular genotypes, $\mathrm{p}>0.050$.

\section{Correlation between RNLS level and CVRFs}

Plasma RNLS level was significantly higher in anuric patients compared to those with preserved RRF $(38.62 \pm 11.59 \mu \mathrm{g} /$ $\mathrm{mL}$ vs $27.23 \pm 10.26 \mu \mathrm{g} / \mathrm{mL}, \mathrm{p}<0.001$ ) (Figure 1), but did not correlate with patient's age, BMI, albumin, glucose and hemoglobin levels. No difference in RNLS concentration between males and females $(33.54 \pm 12.57 \mu \mathrm{g} / \mathrm{mL}$ vs $33.54 \pm 12.20 \mu \mathrm{g} / \mathrm{mL}$, respectively), $\mathrm{p}=1.000$ was found. Plasma RNLS concentration correlated neither with SBP $(\mathrm{r}=-0.110, \mathrm{p}=0.060)$ nor with DBP $(\mathrm{r}=-0.080, \mathrm{p}=0.200)$. There was also no difference in RNLS level between patients with and without hypercholesterolemia $(34.79 \pm 13.44 \mu \mathrm{g} / \mathrm{mL}$ vs $32.51 \pm 11.34 \mu \mathrm{g} / \mathrm{mL}$, $\mathrm{p}=0.133)$ and between smoking and no-smoking individuals (33.24 $\pm 12.14 \mu \mathrm{g} / \mathrm{mL}$ vs $32.51 \pm 11.34 \mu \mathrm{g} / \mathrm{mL}, \mathrm{p}=.465)$. Finally, plasma RNLS correlated neither with hemodialysis adequacy measured by spKt/Vurea $(\mathrm{r}=-0.140, \mathrm{p}=0.239)$ nor with dialysis vintage $(r=0.226, p=0.256)$.

\section{DISSCUSION}

In the present study, which is a continuation and extension of our previous research, we demonstrated for the first time that the effect of rs 10887800 RNLS gene polymorphism (located in intron 6) on plasma RNLS level in HD patients is co-dependent on the presence of comorbid disorders. Hypertesive rs10887800AA carriers had significantly lower RNLS concentration compared to those with AG and GG genotypes. However, similar associations were not observed in CAD+ subgroup. Therefore, we can assume that the impact of rs 10887800 variant on plasma RNLS level, previously reported by us in patients undergoing $\mathrm{HD}$, was due to high prevalence of hypertensive participants in the study cohort [9].

The obtained results suggest that rs 10887800 RNLS polymorphism can affect the risk of HY by the modulation of plasma RNLS level. However, our findings should be interpreted with caution since the pathophysiological role of RNLS in HY remains controversial. First experimental studies demonstrated decreased plasma RNLS level in hypertensive rats after 5/6 nephrectomy [10]. Recombinant RNLS infusion lowered blood pressure [11] and it was through metabolizing circulating catecholamines [12]. Human research on uremic populations brought discrepant results. In the present study we did not observe differences in plasma RNLS level between $\mathrm{HY}+$ and HY- subgroups. Similar findings were obtained in other studies on patients undergoing both hemodialysis [13] and peritoneal dialysis [14]. Furthermore, no association between plasma RNLS level and left ventricular hyperthrophy (LVH), acardiac consequence of inadequateHY control, was observed[15].

TABLE 3. Plasma renalase (RNLS) level according to $R N L S$ genotypes in concomitant comorbidities subgroups.

\begin{tabular}{|c|c|c|c|c|c|}
\hline \multirow{2}{*}{ 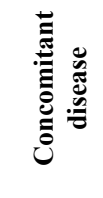 } & \multirow{2}{*}{$\begin{array}{c}\text { Renalase } \\
\text { gene variant }\end{array}$} & \multicolumn{3}{|c|}{ Genotypes } & \multirow{2}{*}{ 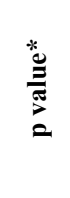 } \\
\hline & & $\mathbf{A A}$ & $\mathbf{A G}$ & GG & \\
\hline \multirow{2}{*}{$\begin{array}{l}\text { HY } \\
(n=259)\end{array}$} & $\begin{array}{l}\text { Rs2576178 } \\
(147 / 95 / 17)\end{array}$ & $32.70 \pm 12.83$ & $33.91 \pm 11.06$ & $34.32 \pm 12.98$ & 0.358 \\
\hline & $\begin{array}{c}\text { Rs10887800 } \\
(69 / 131 / 59)\end{array}$ & $28.93 \mathrm{a} \pm 9.96$ & $34.06 \mathrm{~b} \pm 12.79$ & $36.54 \mathrm{~b} \pm 12.01$ & 0.002 \\
\hline \multirow{2}{*}{$\begin{array}{l}\text { CAD } \\
(n=107)\end{array}$} & $\begin{array}{c}\text { Rs2576178 } \\
(54 / 43 / 10)\end{array}$ & $32.30 \pm 13.17$ & $35.18 \pm 12.24$ & $38.21 \pm 12.18$ & 0.728 \\
\hline & $\begin{array}{c}\text { Rs10887800 } \\
(24 / 51 / 32)\end{array}$ & $31.52 \pm 10.95$ & $34.75 \pm 13.37$ & $34.44 \pm 13.10$ & 0.615 \\
\hline
\end{tabular}

HY - arterial hypertension, CAD - coronary artery disease. RNLS levels presented as means \pm SD. *ANCOVA (analysis of covariance) assessing the effect of $R N L S$ genotypes on RNLS level after adjustment for potentially confounding effect of age, gender, BMI, hemoglobin and albumin level, the presence of hypercholesterolemia and residual renal function.

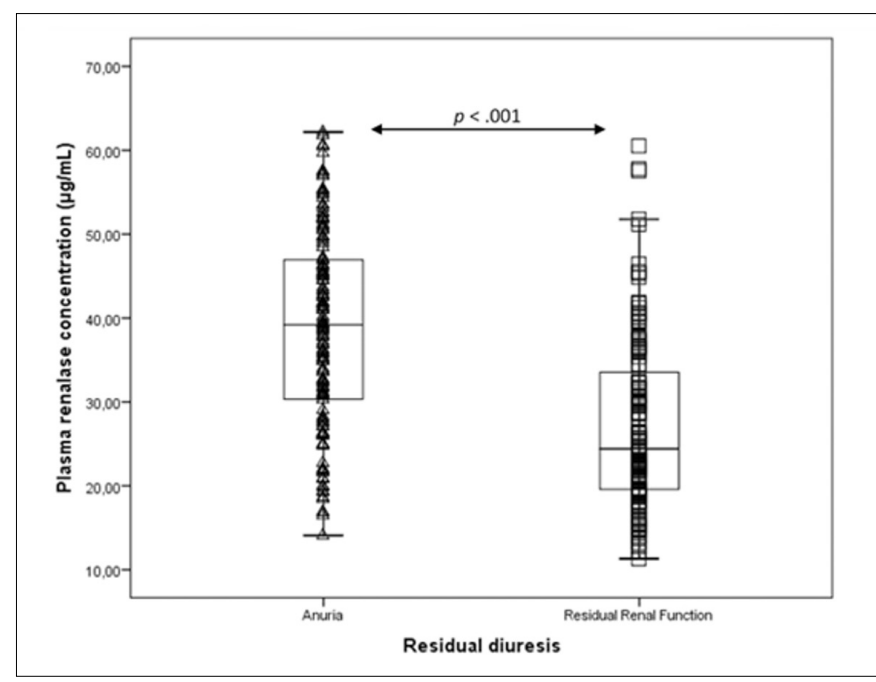

FIGURE 1. The correlation between plasma renalase level and the presence of preserved residual renal function. 
Oppositely, Dziedzic et al. demonstrated a positive correlation between plasma RNLS and mean arterial pressure (MAP) in HD cohort [16].

Our study confirmed literature data that plasma RNLS level is elevated in anuric patients compared to those with preserved RRF, which may be due to its impared clearance. Importantly, loss of diuresis is a well recognized CVD mortality predictor in ESKD patients [17]. Furthermore, we did not observe correlation between plasma RNLS levels and known CVRFs. On the contrary, Zbroch et al. demonstrated a link between plasma RNLS and age in dialyzed individuals. However, the authors concluded that elevated plasma RNLS in older patients could be due to impaired kidney function and high burden of CVDs rather than age itself [18].

The results obtained in the current study are novel. As far as the authors know, no other papers concerning the effect of RNLS polymorphisms on plasma renalase level were published. Furthermore, there are hardly any studies on the mechanism through which RNLS variants affect CVDs risk [19].

Our study has some limitations which have to be pointed out. First, all participants were Caucasian, therefore the experiment should be replicated on different ethnic groups. Secondly, plasma RNLS activity, tissues expression and RNLS concentrations in urine and dialysis fluid were not assessed. Finally, the correlation analyses between $R N L S$ SNPs, CVRFs and catecholamines level should be performed. However, this will be the subject of ongoing studies.

\section{CONCLUSIONS}

Obtained results extend our previous findings and indicate for the first time that the effect of rs10887800 RNLS gene polymorphism on plasma RNLS level in HD patients is co-dependent on the presence of comorbid disorders. Rs 10887800 variant modifies the level of plasma RNLS in hypertensive HD patients but not in those with CAD. Plasma RNLS level is elevated in anuric patients and does not correlate with known CVRFs. The study provides thus a new insight into the potential mechanisms through which $R N L S$ gene variants modulate the risk of CVDs in uremic patients.

\section{REFERENCES}

1. Go AS, Chertow GM, Fan D, et al. Chronic kidney disease and the risks of death, cardiovascular events, and hospitalization. N Engl J Med. 2004;351:1296-305.

2. Burmeister JE, Mosmann CB, Costa VB, et al. Prevalence of cardiovascular risk factors in hemodialysis patients - The CORDIAL Study. Arq Bras Cardiol. 2014;102:473-80.

3. Weiner DE, Tabatabai S, Tighiouart H, et al. Cardiovascular outcomes and all-cause mortality: exploring the interaction between CKD and cardiovascular disease. Am J Kidney Dis. 2006;48:392-401.

4. Longenecker JC, Coresh J, Powe NR, et al. Traditional cardiovascular disease risk factors in dialysis patients compared with the general population: The CHOICE Study. J Am Soc Nephrol. 2002;13:1918-27.

5. Desir GV. Regulation of blood pressure and cardiovascular function by renalase. Kidney Int. 2009;76:366-70.

6. Stec A, Semczuk A, Furmaga J, et al. Polymorphism of the renalase gene in end-stage renal disease patients affected by hypertension. Nephrol Dial Transplant. 2012;27:4162-6.

7. Stec A, Ksiazek A, Buraczynska M. Rs10887800 renalase gene polymorphism is associated with an increased risk of coronary artery disease in hemodialyzed patients. Int Urol Nephrol. 2016;48:871-6.

8. K/DOQI clinical practice guidelines for cardiovascular disease in dialysis patients. Am J Kidney Dis .2005;45(4 Suppl 3):S1-153.

9. Stec A. Rs10887800 renalase gene polymorphism influences the level of circulating renalase in patients undergoing hemodialysis but not in healthy controls. BMC Nephrol. 2017; 18:118.

10. Desir GV. Renalase deficiency in chronic kidney disease, and its contribution to hypertension and cardiovascular disease. Curr Opin Nephrol Hypertens. 2008;17:181-5.

11. Baraka A, El Ghotny S. Cardioprotective effect of renalase in 5/6 nephrectomized rats. J Cardiovasc Pharmacol Ther. 2012;17:412-6.

12. Desir GV, Tang L, Wang P, et al. Renalase Lowers Ambulatory Blood Pressure by Metabolizing Circulating Adrenaline. J Am Heart Assoc. 2012;1: e002634.

13. Zbroch E, Malyszko J, Malyszko JS, et al. Renalase, a novel enzyme involved in blood pressure regulation, is related to kidney function but not to blood pressure in hemodialysis patients. Kidney Blood Press Res. 2012;35:395-9.

14. Zbroch E, Malyszko J, Malyszko J, et al. Renalase in peritoneal dialysis patients is not related to blood pressure, but to Dialysis Vintage. Perit Dial Int. 2012;32:348-51.

15. Oguz EG, Gursoy GK, Yayar O, et al. Increased serum renalase in hemodialysis patients: is it related to left ventricular hypertrophy? Ren Fail. 2016;38:1180-6.

16. Dziedzic M, Petkowicz B, Bednarek-Skublewska A, et al. Relationship between renalase and N-terminal pro-B-type natriuretic peptide (NT proBNP) in haemodialysis patients. Ann Agric Environ Med. 2014;21:132-5.

17. Shemin D, Bostom AG, Laliberty P, et al. Residual renal function and mortality risk in hemodialysis patients. Am J Kidney Dis 2001;38:85-90.

18. Zbroch E, Musialowska D, Koc-Zorawska E, Malyszko J. Age influence on renalase and catecholamines concentration in hypertensive patients, including maintained dialysis. Clin Interv Aging. 2016;11:1545-50.

19. Manning AK, Hivert MF, Scott RA, et al. A genome-wide approach accounting for body mass index identifies genetic variants influencing fasting glycemic traits and insulin resistance. Nat Genet 2012;44:659-69.

Corresponding author

Dr Anna Steć

Department of Nephrology, Medical University of Lublin

8 Jaczewskiego St., 20-954 Lublin, Poland

E-mail: annastec@poczta.onet.pl

tel: +48 (81) 7244704

fax: $+48(81) 7244537$ 